\section{What Happened to Mirror Neurons?}

\author{
Cecilia Heyes $^{1,2}$ (D) and Caroline Catmur ${ }^{3}$ \\ ${ }^{1}$ All Souls College, University of Oxford; ${ }^{2}$ Department of Experimental Psychology, University of Oxford; \\ and ${ }^{3}$ Department of Psychology, Institute of Psychiatry, Psychology, and Neuroscience, King's College \\ London
}

Perspectives on Psychological Science 2022, Vol. 17(1) 153-168

(C) The Author(s) 2021

(c) (1) \&

Article reuse guidelines: sagepub.com/journals-permissions DOI: $10.1177 / 1745691621990638$ www.psychologicalscience.org/PPS (9SAGE

\begin{abstract}
Ten years ago, Perspectives in Psychological Science published the Mirror Neuron Forum, in which authors debated the role of mirror neurons in action understanding, speech, imitation, and autism and asked whether mirror neurons are acquired through visual-motor learning. Subsequent research on these themes has made significant advances, which should encourage further, more systematic research. For action understanding, multivoxel pattern analysis, patient studies, and brain stimulation suggest that mirror-neuron brain areas contribute to low-level processing of observed actions (e.g., distinguishing types of grip) but not to high-level action interpretation (e.g., inferring actors' intentions). In the area of speech perception, although it remains unclear whether mirror neurons play a specific, causal role in speech perception, there is compelling evidence for the involvement of the motor system in the discrimination of speech in perceptually noisy conditions. For imitation, there is strong evidence from patient, brain-stimulation, and brain-imaging studies that mirror-neuron brain areas play a causal role in copying of body movement topography. In the area of autism, studies using behavioral and neurological measures have tried and failed to find evidence supporting the "broken-mirror theory" of autism. Furthermore, research on the origin of mirror neurons has confirmed the importance of domain-general visual-motor associative learning rather than canalized visual-motor learning, or motor learning alone.
\end{abstract}

\title{
Keywords
}

action understanding, associative learning, autism, mirror neurons, neuroscience, social cognition

Ten years ago, mirror neurons were everywhere. In 2011, when Perspectives on Psychological Science published a forum focused on the functions and origins of these fascinating cells (Gallese et al., 2011; Glenberg, 2011a, 2011b), mirror neurons featured in Time magazine and The New York Times, programs about mirror neurons were broadcast by $\mathrm{CNN}$ and the $\mathrm{BBC}$, and more than 200 articles were published in academic journals implicating mirror neurons in, among other functions, action understanding, alexithymia, autism, business management, empathy, imitation, language comprehension, language production, literary mimesis, posttraumatic stress disorder, and schizophrenia. Measured by number of academic publications, interest in mirror neurons peaked 2 years later in 2013 and then began to decline (Fig. 1). Of course, the numbers in Figure 1 are not an infallible measure of scientific interest in mirror neurons. Since 2013, researchers may have begun to use other terms for the same targets of investigation. However, Figure 1 suggests that cognitive scientists are no longer working as actively in this field, or that the mirror-neuron "brand" is losing its appeal, or both and therefore raises the question of what happened to mirror neurons.

Given the extent of public interest in mirror neurons and the liveliness of the controversy they provoked among scientists and philosophers, this question could be fruitfully interpreted in an historical and sociological way. We could ask about the currents in Western society and in contemporary cognitive science that first made mirror neurons "mesmerising" (Heyes, 2010) and then weakened their appeal. But this article takes a more straightforward, natural science approach. After a brief introduction to mirror neurons, we use the questions discussed in the Mirror Neuron Forum (Gallese et al., 2011), concerning the functions and origins of mirror

\section{Corresponding Author:}

Cecilia Heyes, All Souls College, University of Oxford

E-mail: cecilia.heyes@all-souls.ox.ac.uk 


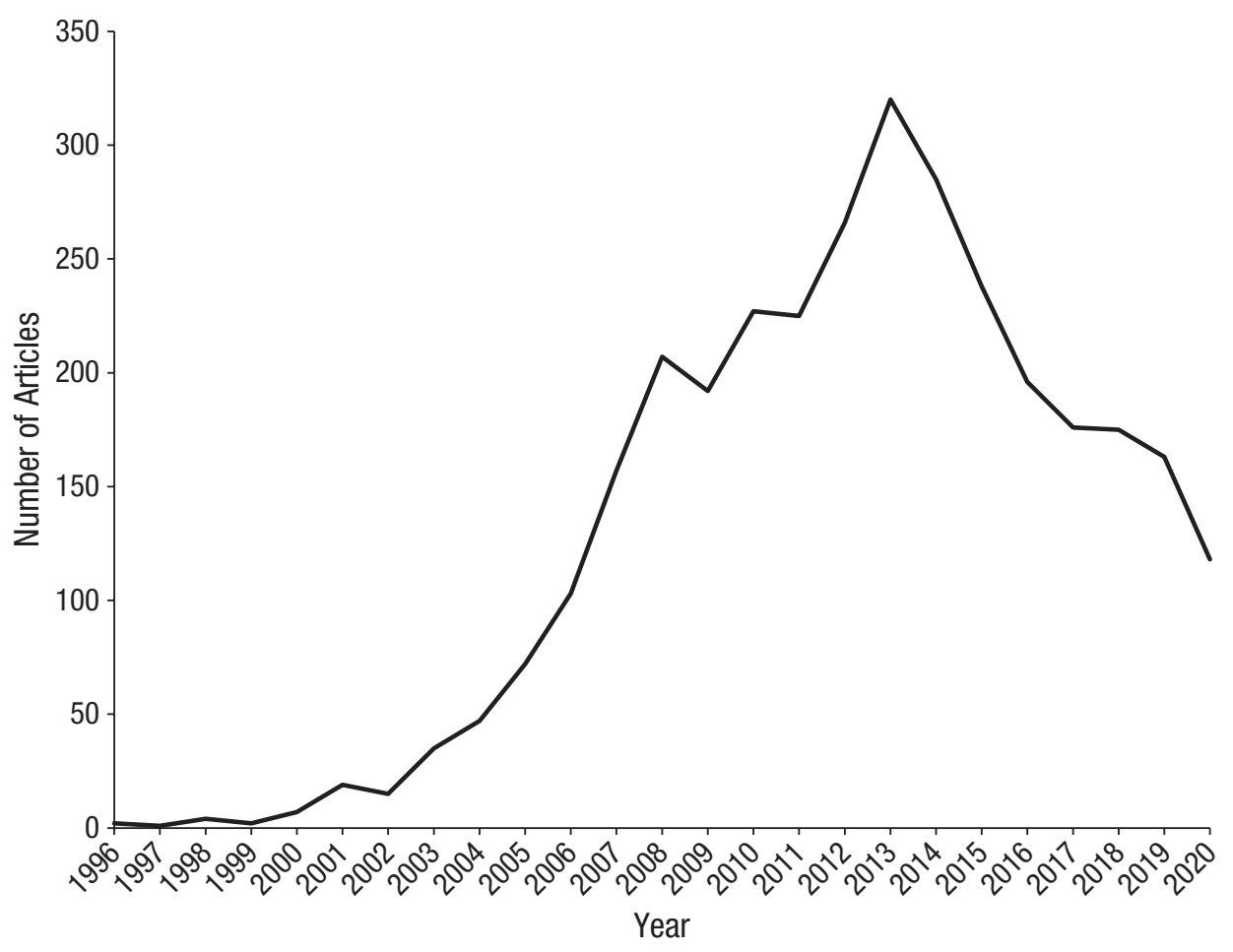

Fig. 1. Number of articles published per year from 1996 to 2020 that included the words "mirror neuron" in the title, abstract, or keywords. Data from Scopus, January 8, 2021.

neurons, to structure a succinct survey of research published in the past 10 years. We then consider whether these recent findings have taken the shine off mirror neurons and, if so, whether that reaction is appropriate. We conclude that although the results of careful empirical research were bound to be disappointing relative to the more grandiose claims, recent work on mirror neurons should encourage further systematic investigation.

\section{Mirror Neuron Basics}

Mirror neurons were discovered by chance in monkeys in 1992 and given their evocative name 4 years later (di Pellegrino et al., 1992; Gallese et al., 1996). Early studies of the field properties of mirror neurons-the sensory and motoric conditions in which they fire-revealed three basic types. Strictly congruent mirror neurons discharge during execution and observation of the same action, for example, when the monkey performs a precision grip and when it passively observes a precision grip performed by another agent. Broadly congruent mirror neurons are typically active during the execution of one action (e.g., precision grip) and during the observation of one or more similar, but not identical, actions (e.g., power grip alone, or precision grip, power grip, and grasping with the mouth). Logically related mirror neurons respond to different actions in observe and execute conditions. For example, they fire during the observation of an experimenter placing food in front of the monkey and when the monkey grasps the food to eat it (di Pellegrino et al., 1992). Strictly and broadly congruent mirror neurons were, from the beginning, of primary interest, and they are what we and most other researchers mean when we use the term "mirror neuron." These cells are intriguing because, like a mirror, they match observed and executed actions; they code both "my action" and "your action."

Monkey mirror neurons are responsive to the observation and execution of hand and mouth actions. The hand actions include grasping, placing, manipulating with the fingers, and holding (di Pellegrino et al., 1992; Gallese et al., 1996). The mouth actions include ingestive behaviors such as breaking food items, chewing, and sucking and communicative gestures such as lip smacking, lip protrusion, and tongue protrusion (Ferrari et al., 2003).

Mirror neurons were originally found using singlecell recording in area $\mathrm{F} 5$ of the ventral premotor cortex (di Pellegrino et al., 1992; Gallese et al., 1996) and the inferior parietal lobule (Bonini et al., 2010; Fogassi et al., 2005) of the monkey brain. Subsequently, they were found not only in these "classical" areas but also in nonclassical areas, including primary motor cortex (Dushanova \& Donoghue, 2010; Tkach et al., 2007) and dorsal premotor cortex (Tkach et al., 2007). 
Early research with human participants used functional MRI (fMRI) to show spatial overlap in the areas of ventral premotor cortex and inferior parietal lobule that are active when people observe and execute movements (Buccino et al., 2001; Decety et al., 1997; Grezes \& Decety, 2001; Rizzolatti et al., 1996). This was not conclusive evidence of the existence of human mirror neurons because the spatial overlap could have been due not to neurons that each respond both to observation and execution of action (mirror neurons) but to clusters of neurons each responding either to action observation or to action execution (Dinstein, 2008; Dinstein et al., 2007). By 2011, doubts about the presence of mirror neurons in the human brain had been assuaged by studies using single-cell recording in presurgical patients (Mukamel et al., 2010) and the repetition suppression fMRI procedure in healthy volunteers (Kilner et al., 2009). Like monkey mirror neurons, evidence consistent with the existence of human mirror neurons has been found in both classical areas-ventral premotor cortex and inferior parietal lobule-and nonclassical areas, including dorsal premotor cortex, superior parietal lobule, cerebellum (Molenberghs et al., 2012), supplementary motor area, and medial temporal lobe (Mukamel et al., 2010).

Research using single-cell recording (and to some extent, repetition suppression) suggests that mirror neurons are typically present in adult human brains. However, this research does not license the inference that mirror neurons are always or usually responsible for spatial overlap in fMRI responses during the observation and execution of action. Consequently, it has become common to use terms such as "the mirrorneuron system" and "mirror-neuron brain areas" to refer to regions of the brain that are active during action observation and execution and/or for which there is evidence of the presence of mirror neurons. As reviewers, we have adopted the latter of these conventions, but note that these terms are unsatisfactory in at least two respects. First, it is not clear in what sense the areas containing mirror neurons constitute a system. Second, it is likely that only a few of the neurons in each of these areas have mirror properties. For example, fewer than $10 \%$ of the neurons studied in di Pellegrino et al.'s (1992) seminal article showed "strict" or "broad" congruence in their firing patterns to observed and executed actions, and although some single-unit studies have reported higher proportions of mirror neurons, the nature of the single-unit technique makes it problematic to estimate the true prevalence of mirror neurons in any brain area (see also Kilner \& Lemon, 2013). These issues should be borne in mind when considering the results of neuroimaging and neurostimulation studies discussed in this review.
From their discovery in 1992, theorizing about the function of mirror neurons was dominated not by computational modeling and experimental intervention but by consideration of their field properties. Defining functions broadly and in everyday language, researchers reflected on what neurons responsive to similar observed and executed actions would be "good for," what kinds of psychological tasks they might be able to fulfill. In some cases, this strategy produced hyperbole. Mirror neurons were hailed as "cells that read minds" (Blakesee, 2006), "the neurons that shaped civilization" (Ramachandran, 2009), and a "revolution" in understanding social behavior (Iacoboni, 2008). But most researchers, including the group in Parma that discovered mirror neurons, focused on four realistic possibilities: action understanding, speech perception, imitation, and their potential dysfunction in autism. Each of these four hypotheses about the function of mirror neurons was debated in the Mirror Neuron Forum (Gallese et al., 2011; referred to hereafter as the forum) alongside a key question about their origins: Do mirror neurons get their characteristic visual-motor matching properties from learning?

\section{Functions \\ Action understanding}

In his lucid summary analysis of the forum, Glenberg (2011b) concluded in relation to action understanding that there was broad agreement that mirror neurons, or a mirror-neuron system, "plays some role in action processing" (p. 408) but no consensus about what that role might be. It could be relatively low level; mirror neurons may contribute to action selection or to action recognition, helping to distinguish one type of action from another (e.g., precision grip from power grip). Alternatively, mirror neurons may have a high-level function in action processing, enabling "understanding from within" (Rizzolatti \& Sinigaglia, 2010) or inferences about actors' mental states. Since 2011, advances in addressing this issue have come mainly from two broad lines of evidence: the use of multivoxel pattern analysis in fMRI to "decode" the information represented within and across brain areas and the use of patient studies and neurostimulation to investigate the causal role of mirror-neuron brain areas for action understanding.

Multivoxel pattern analysis has revealed that "mirror" areas including premotor cortex encode concrete representations of observed actions (e.g., the action involved in opening a particular bottle) rather than abstract, higher level representations (e.g., the goal "to open"; Wurm \& Caramazza, 2019; Wurm \& Lingnau, 2015). These findings are consistent with the involvement of 
mirror neurons in lower level processing of observed actions.

However, any such involvement does not entail that mirror neurons play a causal role in action processing. The evidence in this case is still rather mixed. Studies of individuals born without upper limbs indicate that action recognition can take place without motor representations of the relevant effectors (Vannuscorps \& Caramazza, 2016), and some stroke patients can identify actions despite damage to mirror-neuron brain areas (Tarhan et al., 2015), although a meta-analysis of previous findings indicates that such patients do show impairments in action identification (Urgesi et al., 2014).

Patient studies can be hard to interpret, however, because of heterogeneity in the damage incurred and the acquisition over time of compensatory strategies. Temporary disruption of brain function using neurostimulation can therefore provide convergent evidence that a particular brain area plays a causal role in relation to a particular cognitive function. One prominent neurostimulation study indicated that premotor cortex was necessary for identification of the intentions underlying observed actions (Michael et al., 2014). However, in that study, premotor cortex stimulation also disrupted perceptual matching of the observed actions. It is possible, therefore, that the disruption to intention identification was the result of disruption to low-level action processing and that premotor cortex does not play a direct, causal role in intention reading (Catmur, 2014).

On the basis of evidence including that summarized above, Thompson and colleagues' (2019) recent review of the putative contribution of mirror neurons to action understanding concluded that any involvement of mirror neurons appears to be confined to lower level processing of observed actions (e.g., aiding action discrimination or recognition). In particular, they found no compelling evidence for the involvement of mirror neurons, or mirror-neuron brain areas, in higher level processes such as inferring other people's intentions from their observed actions.

\section{Speech perception}

Four contributors to the forum (Gallese et al., 2011) Gernsbacher, Gallese, Hickok, and Iacoboni-agreed that the motor system has some role in speech perception, but they disagreed about the type and magnitude of the motor system's role and about whether mirror neurons in particular are important (Glenberg, 2011b).

Neuroimaging data indicate that mirror-neuron brain areas respond during speech perception. For example, Callan and colleagues (2014) demonstrated that responses in ventral premotor cortex during a vowel-identification task were enhanced when the signal-to-noise ratio was reduced, suggesting that such responses may improve speech discrimination in perceptually noisy conditions. Measurement of motor cortex excitability has also been used to investigate the involvement of motor areas in speech perception. Motor cortical representations of speech effectors (e.g., lips or tongue) are enhanced during the perception of speech in noise (Nuttall et al., 2016, 2017; but see Panouilleres et al., 2018, for a contrasting result). This enhancement may have functional implications for speech perception ability: Participants with greater motor mirroring of perceived speech showed better ability to discriminate speech in noise (d'Ausilio et al., 2014).

However, evidence from patient studies casts doubt on whether the motor system is causally involved in speech perception. If speech perception requires perceived speech to be matched with motor commands for the production of speech, then one should find speech perception impairments in patients who have impairments in speech production as a result of brain lesions. In contrast to this prediction, a series of studies has demonstrated intact speech sound discrimination in patients with speech production difficulties (Hickok et al., 2011; Rogalsky et al., 2011; Stasenko et al., 2015).

A final line of evidence comes from brain-stimulation studies. Restle and colleagues (2012) demonstrated that facilitatory brain stimulation to the inferior frontal gyrus-a classical mirror-neuron brain area-improved participants' accuracy in repeating unfamiliar foreign speech sounds. They argued that this indicates the role of the inferior frontal gyrus in matching perceived speech to produced speech, but this result cannot reveal whether the crucial role of this brain area is in speech perception, speech production, or the matching process itself. Furthermore, because this study did not include a control task, it is unclear whether stimulation of this brain area had a specific effect on speech processing or whether any complex sensorimotor task might have been improved by such stimulation. However, a series of subsequent studies has shown that stimulation of motor (Rogers et al., 2014; Smalle et al., 2015) or premotor cortex (Nuttall et al., 2018) affects speech perception ability, in particular for distorted speech (Nuttall et al., 2018), and one of these studies included a control task, which permits the conclusion that the stimulation had a specific effect on perception of speech but not nonspeech sounds (Rogers et al., 2014).

In summary, there appears to be reasonably strong evidence for the involvement of the motor system (including premotor mirror-neuron brain areas as well as motor cortex) in the discrimination of speech in perceptually noisy conditions. However, this conclusion is not yet supported by the patient data. A priority for future research, therefore, is to test whether patients 
with premotor lesions are impaired at discrimination of speech from noise.

\section{Imitation}

Of the functions discussed in the forum, imitation attracted the strongest consensus. It was agreed that although early work on the relationship between mirror neurons and imitation had involved some dubious definitions and inferences, "when imitation [is] defined in terms of action topography [how body parts move relative to one another], most agree mirror neurons contribute" (Glenberg, 2011b, p. 409). This consensus was due in large measure to two studies showing that repetitive transcranial magnetic stimulation, a disruptive intervention, of the inferior frontal gyrus, a mirrorneuron brain area, selectively impaired imitative behavior (Catmur et al., 2009; Heiser et al., 2003).

Causal methodologies, including brain-stimulation and patient studies, have continued to support the consensus that mirror-neuron brain areas contribute to imitation. Two studies in which facilitatory brain stimulation to inferior frontal gyrus were used demonstrated improvements in vocal imitation and naturalistic mimicry (Hogeveen et al., 2015; Restle et al., 2012), whereas inhibitory stimulation to the inferior parietal lobule slowed participants in an instructed imitation task (Reader et al., 2018). Inhibitory stimulation of the inferior frontal gyrus also disrupted automatic imitation (Newman-Norlund et al., 2010), but this effect was not specific to human body movements, and similar disruption was found for nonbiological stimuli.

Binder and colleagues (2017) demonstrated that patients with apraxia were impaired on an instructed imitation task and that this impairment was associated with lesions to a set of brain areas thought to contain mirror neurons, including the left postcentral gyrus, intraparietal sulcus, and inferior frontal cortex. A similar result was reported by Frenkel-Toledo et al. (2016), who found imitation impairments to be associated with lesions to the left inferior and superior parietal lobules and postcentral gyrus.

Data from causal studies such as these have been complemented by a series of fMRI studies over the past decade, which demonstrate greater responses in mirrorneuron brain areas during imitation than during other closely matched tasks (e.g., Campbell et al., 2018; Mainieri et al., 2013; Mengotti et al., 2012; Ocampo et al., 2011).

\section{Autism}

In marked contrast with imitation, the forum unearthed "huge disagreement on autism" (Glenberg, 2011b). Although Gallese defended the view that "impaired motor cognition," rather than mirror neurons, contributes to the autistic ${ }^{1}$ phenotype, Iacoboni stood by the more specific "broken-mirror theory" (Iacoboni \& Dapretto, 2006; Oberman \& Ramachandran, 2007; Williams et al., 2001; but see Southgate \& Hamilton, 2008), citing a range of brain-imaging studies suggesting that people with autism have abnormal activity in mirror-neuron areas of the brain. Gernsbacher contested all of this evidence, highlighting methodological problems and replication failures, whereas Heyes, also skeptical about the broken-mirror theory, focused on evidence that people with autism show intact (Bird et al., 2007; J. L. Cook \& Bird, 2012; Gowen et al., 2008; Press et al., 2010) and sometimes exaggerated (Spengler et al., 2010) automatic imitation.

A systematic review in 2013 of neuroscientific evidence concluded that there was "little evidence for a global dysfunction of the mirror system in autism" (Hamilton, 2013, p. 91). Studies published since that review, in which a range of techniques were used to investigate neural responses to observed actions and imitation (the cognitive function thought to rely most strongly on such responses), support this conclusion.

A popular technique to measure motor system responses during action observation is mu suppression, an electroencephalographic (EEG) measure of the reduction in coherence in certain frequency bands that occurs both when performing and when observing actions. However, the use of this technique to index mirror-neuron responses has been criticized on the grounds that it measures attentional (Hobson \& Bishop, 2016, 2017) and somatosensory (Coll et al., 2015, 2017), rather than motor, responses. Notwithstanding these critiques, recent studies of mu suppression during action observation in autism have shown no differences from neurotypical controls (Bernier et al., 2013; Ruysschaert et al., 2014).

In contrast, fMRI of neural responses during action observation indicates some differences between autistic and neurotypical participants. A recent meta-analysis of six fMRI studies of action observation and imitation indicated that participants with autism showed greater responses in bilateral fronto-parietal regions than participants without autism (Yang \& Hofmann, 2016), although another study showed no differences in neural responses during action observation (Pokorny et al., 2015). These data suggest some differences in responses during action observation, but they are not consistent with a broken-mirror account of autism; if anything, they point to greater neural responses in mirror-neuron brain areas during action observation in people with autism compared with those without autism. Furthermore, although these responses are in brain areas thought to contain mirror neurons, none of these 
researchers used techniques that permit the definitive conclusion that such responses are due to mirror neurons instead of other neurons colocated in these brain areas.

Techniques that measure motor representations of specific actions (e.g., grasping) are potentially more informative in this respect. Recent studies in which motor-evoked potentials were used to measure motor cortical excitability during action observation provide mixed evidence for differences between autistic and neurotypical participants. Enticott and colleagues (2012) reported a smaller increase in motor cortical excitability in participants with autism compared with neurotypical control participants when viewing hand grasps. However, a later study found no differences on the same measure when observing socially relevant hand actions (Enticott et al., 2013). Previous claims of disrupted mirror responses in autism based on electromyographic evidence (Cattaneo et al., 2007) have also come under scrutiny, and a series of methodological critiques has cast doubt on the interpretation of previous data (Pascolo \& Cattarinussi, 2012; Ruggiero \& Catmur, 2018).

Finally, behavioral measures of imitation have also provided little evidence for a broken-mirror account of autism. Although one study reported some differences in instructed imitation (Cossu et al., 2012), a task with many demands unrelated to mirror neurons, the majority of recent studies have found either no difference in imitation between autistic and neurotypical participants or greater imitation in people with autism (Gordon et al., 2020; Schulte-Ruther et al., 2017; Schunke et al., 2016; Sowden et al., 2016). Overall, therefore, the past 10 years of research have produced no compelling evidence for the claim that autism is associated with mirror-neuron dysfunction.

\section{Origins}

Contributors to the forum also debated the origins of mirror neurons, addressing the question of whether mirror neurons get their characteristic visual-motor matching properties from learning. Heyes argued that mirror neurons get their matching properties via standard mechanisms of sensorimotor associative learning. They start out as motor neurons, active only during the performance of action. Then, through correlated experience of seeing and doing the same actions-in the context of self-observation (e.g., an infant watches his or her hand own in motion) and social interactions in which the same movements are repeatedly both observed and executed (e.g., pat-a-cake; Heyes, 2001) these motor neurons become strongly connected to visual neurons tuned to similar actions. Consequently, what was once a motor neuron becomes a mirror neuron-responsive to both the sight and performance of an action. Iacoboni agreed that visual-motor learning is likely to be important but saw signs that it is "canalized" by a genetic predisposition to develop mirror neurons (Del Giudice et al., 2009). Gallese went further, arguing that there is an "innate" or "genetically predetermined" (Gallese et al., 2011, p. 384) propensity to develop mirror neurons that is facilitated not primarily by visual-motor learning but by motor experience before and after birth (Gallese et al., 2009). Summarizing the debate about origins, Glenberg (2011b, p. 409) identified as a key question "the degree to which neonatal imitation is a reliable phenomenon."

\section{Sensorimotor learning}

In the past decade, more evidence has emerged that learning plays an important role in the development of mirror neurons (Brunsdon et al., 2020; Catmur et al., 2011; Copete et al., 2016; de Klerk et al., 2015; Fitzgibbon et al., 2016; Furukawa et al., 2017; Guidali et al., 2020; Hou et al., 2017; McKyton et al., 2018; Orlandi et al., 2017; Press et al., 2012; Wiggett et al., 2012; Zazio et al., 2019). Some of the recent studies have reported greater activity in mirror-neuron brain areas in pianists and dancers than in people who lack such expertise during observation of musical performance and dance, respectively (Furukawa et al., 2017; Hou et al., 2017; Orlandi et al., 2017). These studies are of interest because they indicate that activity in mirrorneuron brain areas is affected by long-term learning under naturalistic conditions, but they do not indicate what kind of learning is important. For example, dancers may show greater mirror-neuron brain area activity than control participants during dance observation because the dancers have watched more dance movements (sensory learning), performed more dance movements (motor learning), and/or watched more dance movements while performing similar dance movements (sensorimotor learning).

Experiments that were designed to isolate the kind of learning involved in mirror-neuron development have suggested that sensorimotor learning is crucial (Catmur et al., 2011; de Klerk et al., 2015; Fitzgibbon et al., 2016; Guidali et al., 2020; Press et al., 2012; Wiggett et al., 2012). For example, replicating and extending earlier work with a similar design (e.g., Catmur et al., 2007, 2008), Wiggett et al. (2012; see also Brunsdon et al., 2020) found using fMRI that mirrorneuron brain areas were more strongly activated by observation of hand movement sequences in participants who had simultaneously observed and executed the movements (sensorimotor learning) than in participants who had either observed the movements without 
performing them (sensory learning) or performed the movements without observing them (motor learning). Furthermore, using paired-pulse transcranial magnetic stimulation (TMS), Catmur et al. (2011) confirmed that novel sensorimotor experience of the kind given by Wiggett et al. acts on mirror responses. They showed that "counter-mirror" training (in which participants performed index-finger movements while observing little-finger movements and vice versa) reversed mirror responses (e.g., resulted in greater activation of an index-finger muscle during observation of little-finger movement than during observation of index-finger movement) via the same connections between premotor and motor cortex that were responsible for mirror effects before training (e.g., greater activation of an index-finger muscle during observation of index-finger movement than little-finger movement).

Responding to a study in which counter-mirror training yielded later effects on motor excitability than mirror training (Barchiesi \& Cattaneo, 2013; see also Ubaldi et al., 2015), Cavallo et al. (2014), like Catmur et al. (2011), found that mirror responses and counter-mirror responses followed the same time course. Another TMS study found that counter-mirror responses can be induced by instruction alone (Bardi et al., 2015). However, it is unlikely that instructional learning, rather than sensorimotor learning, was responsible for the training effects reviewed above because (a) in the study by Bardi et al. (2015), participants were tested immediately after instruction, whereas in the earlier studies they were tested $24 \mathrm{hr}$ after both instruction and sensorimotor training, and (b) training effects have been observed in uninstructed infants (de Klerk et al., 2015).

The training studies described above involved adult participants, but there is also now evidence that sensorimotor learning is important in the early development of mirror responses. Using EEG recordings of sensorimotor $\alpha$ suppression as an index of mirrorneuron activity, de Klerk et al. (2015) found in 7-monthold infants, who could not yet walk, that mirror responses during observation of stepping movements increased with the amount of sensorimotor experience they had received in earlier training sessions. Infants who had frequently seen their own stepping movements while performing those movements showed greater $\alpha$ suppression than infants who had relatively little correlated experience of seeing and doing the stepping movements. De Klerk et al. did not find similar effects of sensory experience (observing stepping) or motor experience (making stepping movements) on $\alpha$ suppression, suggesting that at least in this study, $\alpha$ suppression indexed the sensorimotor matching function of mirror neurons rather than purely attention or arousal.
The idea that motor learning alone is sufficient to change the properties of mirror neurons (Gallese et al., 2009) has not been supported. The study by de Klerk et al. (2015) failed to find a relationship between the frequency with which infants performed stepping movements during training and the extent of sensorimotor $\alpha$ suppression during observation of stepping movements after training. Yet more striking, using imitation as a behavioral index of mirror-neuron activity, McKyton et al. (2018) found reduced automatic imitation in newly sighted children who suffered from dense bilateral cataracts from early infancy and were surgically treated only years later. These children, who had been deprived of sensory and sensorimotor experience of action but not of motor experience, were less inclined than control children to imitate task-irrelevant hand actions.

In addition to showing that sensorimotor learning is important for mirror-neuron development, recent research suggests that in everyday life, much of this learning occurs in the context of social interactions between infants and their caregivers. The extent to which mothers imitate infant facial expressions at 2 months postpartum predicts EEG $\alpha$ suppression at 9 months during observation of the same facial expressions (Rayson et al., 2017; see also Markodimitraki \& Kalpidou, 2019; Murray et al., 2018). Furthermore, this relationship is action specific. De Klerk et al. (2019) found that parental imitation of facial expressions predicted infant imitation of facial but not hand movements, implying that parental imitation supports mirror-neuron development through learning of specific sensorimotor associations (e.g., between the sight and performance of mouth opening) rather than by enhancing attention to body movements or social motivation.

\section{Is the sensorimotor learning genetically canalized?}

The importance of sensorimotor learning for the development of mirror neurons is now well established, but questions remain about the character of this learning. The "associative account" maintains that the sensorimotor learning that builds mirror neurons is of exactly the same kind as the learning that produces Pavlovian and instrumental conditioning; it is a computationally undemanding, domain-general process that forges excitatory and inhibitory links between simple event representations (R. Cook et al., 2014; Heyes, 2001; Keysers \& Perrett, 2004). In contrast, the "canalization account" (Del Giudice et al., 2009; Gallese et al., 2009), supported by Iacoboni and Gallese in the forum, suggests that monkeys and humans genetically inherit a specific 
propensity to acquire mirror neurons. On this view, the sensorimotor learning that contributes to mirror-neuron development is domain specific - it involves computations distinct from those involved in standard conditioningand/or the learning is primed for the development of mirror neurons (given a head start by genetically inherited behavioral mechanisms).

A few studies in the past 10 years have addressed the domain generality of the sensorimotor learning involved in mirror-neuron development. Consistent with the associative account, these have indicated that like standard conditioning, mirror-neuron learning depends on contingency as well as contiguity (Cooper et al., 2013) and shows a distinctive pattern of contextual modulation (R. Cook et al., 2012). However, as Glenberg (2011b) predicted, the majority of research bearing on the associative and canalization accounts has focused on neonatal imitation. Given the evidence that mirror neurons contribute to imitation (see above), reliable evidence that newborns can imitate before they have had the opportunity for relevant sensorimotor learning would suggest that the development of mirror neurons is canalized or genetically predetermined.

A set of 10 studies from one research group, eight of them published since the forum, claimed to provide evidence of imitation in newborn monkeys (Ferrari et al., 2006, 2009; Kaburu et al., 2016; Paukner et al., 2011, 2014, 2017; Simpson et al., 2013, 2014, 2016; Wooddell et al., 2019). These studies did not use the "cross-target" procedure, which both enthusiasts and skeptics have agreed is necessary to detect imitation in newborns (e.g., Meltzoff, 1996; Meltzoff \& Moore, 1977; Oostenbroek et al., 2016; Ray \& Heyes, 2011; Redshaw, 2019; Whiten, 2002). For example, when testing for imitation of tongue protrusion and lip smacking, they did not use these behaviors as controls for one another. Instead of looking for a higher frequency of tongue protrusion than of lip smacking in infants who had just observed tongue protrusion and a higher frequency of lip smacking than of tongue protrusion in infants who had just observed lip smacking, they reported, for example, a higher frequency of tongue protrusion after observation of tongue protrusion than after observation of a rotating disk. An effect of this kind could be due not to imitation of tongue protrusion but to a biological, social stimulus eliciting more behavior of all kinds than a nonbiological, asocial stimulus. Pointing out this problem alongside a number of others (e.g., multiple comparisons without correction), Redshaw (2019) reanalyzed the data from the full corpus of 10 neonatal monkey studies. Applying the cross-target methodology, the reanalysis found no evidence whatever of imitation in newborn monkeys.
Recent work with human neonates points in the same direction. In a study with unprecedented power, conducted in Brisbane, Oostenbroek et al. (2016) tested more than 100 infants longitudinally at 1, 3, 6, and 9 weeks of age in a cross-target procedure involving a wide range of targets. They recorded the frequencies of nine target actions-tongue protrusion, mouth opening, happy expressions, sad expressions, index-finger protrusion, grasping, MMM sound, EEE sound, and tongue click-while infants observed 11 movement stimuli-an adult performing each of the nine actions and two object movements (spoon protruding through a tube and box opening). The results of the Brisbane study were wholly negative: In no case did the infants consistently perform a target action more often while observing the same action than while observing all of the alternative actions.

Previous failures to find neonatal imitation have been attributed to methodological factors-for example, the use of an inappropriate model, an inadequate response interval, or suboptimal statistical procedures. In a recent meta-analysis of neonatal imitation research by the Brisbane group, encompassing 336 effect sizes dating back to 1977 , researchers sought and did not find a modulating influence of 13 methodological factors previously cited as reasons for replication failure (Davis et al., 2021). However, the meta-analysis did find a modulating effect of "researcher affiliation," in which a small number of laboratories are more likely than others to find large positive effects. Furthermore, across the whole data set, there was a relationship between standard error and effect size indicative of publication bias (i.e., suggesting that smaller studies have been conducted, found no evidence of neonatal imitation, and not been published).

Reanalyzing the data from the Brisbane study using a more liberal statistical method, Meltzoff et al. (2018; see also Oostenbroek et al., 2018) found evidence of imitation for one of the nine target actions-tongue protrusion. Although consistent with other reviews and meta-analyses of neonatal imitation data (e.g., Anisfeld, 1996; Jones, 2006; Ray \& Heyes, 2011), this result does not uphold the historical claim that newborns are capable of voluntary imitation of a range of actions (Meltzoff \& Moore, 1977; see also Keven \& Akins, 2017) or support the view that mirror neurons are learned via a canalized or genetically predetermined process.

Rather than supporting canalization, one study of young human infants provided evidence that the development of imitation (and by inference, mirror neurons) depends on unspecialized, unconstrained associative learning. Reeb-Sutherland et al. (2012) found that associative learning ability at 1-month postpartum, measured 
using a delay- eyeblink-conditioning paradigm, predicted performance on a range of imitation tasks at 9 months of age.

\section{Reflection}

In the past 10 years, there has been significant progress in resolving the questions debated in the Mirror Neuron Forum (Gallese et al., 2011). Regarding action understanding, multivoxel pattern analysis, patient studies, and research using TMS now suggest that mirrorneuron brain areas contribute to low-level processing of observed actions (e.g., distinguishing types of grip) but not directly to high-level action interpretation (e.g., inferring actors' intentions). In terms of speech perception, although it remains unclear whether mirror neurons play a specific, causal role in speech perception, there is now compelling evidence for the involvement of the motor system (including premotor mirror-neuron brain areas as well as primary motor cortex) in the discrimination of speech in perceptually noisy conditions. Regarding imitation, building on research published before 2011, researchers conducting patient, TMS, and fMRI studies have found strong evidence that mirror-neuron brain areas play a causal role in behavioral copying of body movement topography. Finally, concerning autism, researchers using behavioral and neurological measures have tried and failed to find evidence for the broken-mirror theory of autism. Instead, there are intriguing signs that under some conditions, people with autism have stronger mirror responses than neurotypical control participants. Alongside these developments, research on the origin of mirror neurons has confirmed the importance of domain-general visual-motor associative learning rather than canalized visual-motor learning or motor learning alone. Specifically, major studies assessing "the degree to which neonatal imitation is a reliable phenomenon" (Glenberg, 2011b) have shown that it is not reliable at all.

These findings are disappointing relative to early newspaper headlines. It turns out that mirror neurons are not "Cells That Read Minds" (Blakesee, 2006), they do not alone explain "what makes humans social" (Lehrer, 2008), and they have not been able to "do for psychology what DNA did for biology" (Ramachandran, 2009). But it is unlikely that any serious cognitive scientist or neuroscientist would be surprised that mirror neurons have not lived up to these sensational claims. The puzzle is why mirror neurons have so inflamed the popular imagination. We speculate that two factors are important. First is the deep historical pull of atomism. Mirror neurons are small and apparently indivisible; they combine sensory and motor properties in a single unit. From ancient Greece to particle physics, there is a long tradition in which atoms of this kind are understood to be the building blocks of reality. Immersed in this tradition, people may be captivated by the idea that simple, tidy mirror neurons explain the distressing complexities of the social world-including political strife, drug addiction, pornography, and responses to media violence (Bocher et al., 2001; Iacoboni, 2008). Second, some descriptions of mirror neurons imply telepathy. If mirror neurons mediate "understanding from within" (Rizzolatti \& Sinigaglia, 2010), a "pre-conceptual and pre-linguistic form of understanding," which can "overcome all linguistic and cultural barriers" (Rizzolatti \& Sinigaglia, 2008; p. xiii), they allow an effortless, wordless form of communication that is a lot like telepathy. Given ancient links between mirrors, oracles, and divination (e.g., Orofino, 1994), even the name mirror neurons may pump the intuition (Dennett, 1984) that these cells give direct, transparent access to other minds (Heyes, 2010).

Figure 1 suggests that even if public enthusiasm for mirror neurons has been sustained, scientific interest began to decline in 2014. Two high-profile reviews were published in that year. One of them, a target article with commentaries in Behavioral and Brain Sciences, did not contest the existence of mirror neurons, or that they contribute to social behavior, but marshaled evidence that they are forged by sensorimotor associative learning (R. Cook et al., 2014). This evidence challenged the view that mirror neurons are a biological adaptation - that they evolved via genetic mechanisms for action understanding, speech, imitation, or any other function. The other review, a book titled The Myth of Mirror Neurons, was more skeptical. It argued that because mirror neurons are products of associative learning, they could not mediate action understanding or any other cognitive function (Hickok, 2014). The impact of these two publications should not be overestimated. They distilled and developed insights and concerns that had been emerging over the preceding years. But it is plausible that they precipitated the subsequent decline of mirror-neuron research.

Should the decline be resisted, or should it be hoped that the trend apparent in Figure 1 continues until mirror neurons are a thing of the past? We support resistance for two reasons. First, even if the mirror-neuron boom was fueled by less than rational currents of thought (e.g., atomism and telepathy) inside as well as outside science, it would not be rational to allow mirror neurons to go bust. This field has produced substantial findings, many summarized in this article, which should not be dismissed just because mirror neurons are "the most hyped concept in neuroscience" (Jarrett, 2012). Second, in our view, much of the skepticism about 
mirror neurons is based on a misunderstanding. The discovery that mirror neurons are forged by associative learning does not imply that they are without function. It suggests they are by-products with respect to genetic evolution, but by-products can be very useful indeedin the oil business and in the brain. Consider the area of the left fusiform gyrus that mediates identification of visual word forms. Literacy emerged late in human history, only 5,000 to 6,000 years ago, making it clear that the visual word form area was not designed by genetic evolution to enable reading. It is a by-product of genetic adaptation for the discrimination of visually complex objects-just as mirror neurons are a byproduct of genetic adaptation for learning about predictive relationships-but literacy is hugely important as a means of relating to and learning from other people; literacy is a social cognitive function (Heyes, 2018).

Our review of mirror-neuron research in the past 10 years and the critiques discussed in this section have several implications for future research. In relation to mirror-neuron functions, research on low-level action discrimination is more likely to make progress than continuing effort to find a direct role for mirror neurons in high-level action interpretation. Likewise, imitation looks more promising than speech perception, andgiven the strength of the evidence that mirror neurons contribute to imitation and the lack of evidence that autism is due to a broken mirror-dyspraxias are a more promising target than autism for research with clinical applications. The idea that mirror neurons contribute to imitation was dismissed at an early stage on the grounds that monkeys, the first species in which mirror neurons were identified, cannot imitate (Rizzolatti \& Craighero, 2004). This argument assumed that imitation involves copying an entirely novel action guided by understanding of the model's intentions, a definition so rich that it implies imitation is rare even in adult humans (Heyes, as cited in Gallese et al., 2011). Defining imitation in a way that is more common in cognitive science, as copying the topography of body movement, the associative account of the origin of mirror neurons implies that any animal capable of sensorimotor associative learning has the potential to develop mirror neurons and to imitate. Humans are better imitators than other animals, including monkeys, because sociocultural experience (e.g., synchronous dance and sporting activities, being imitated by others) provides humans with matching sensorimotor experience for a broader range of actions (R. Cook et al., 2014). In retrospect, it seems that the rich definition of imitation diverted attention from one of the most important functions of mirror neurons.

As for future research on the origins of mirror neurons, there is still much to be discovered about the sources and developmental timing of the sensorimotor experience that builds mirror neurons, how this varies across cultures, and how this information might be used for clinical and educational interventions. More broadly, investigation of how mirror neurons are woven into computational-neurological systems could provide valuable clues about how other cognitive systems are assembled through learning. When a function is "hardwired" or "innate," the construction work is done by evolution acting on genetic variants and lost in the mists of time, but when the construction is done by learning, it can be studied in creatures alive today (Heyes, 2018).

Turning from targets of study to methods, it is clear that causal methodologies, such as TMS, have more power to illuminate functions than correlational methodologies, and if it is concluded that the unitary character of mirror neurons is of crucial importance (see below), the use of more single-unit recording would be desirable. The potential for such recording would be greatly expanded by the development of rodent models using sensorimotor training (Heyes, 2013).

Thinking more broadly about methodology, research on mirror neurons would benefit greatly from extension of a system-level, computational approach of the type advanced by Hickok and Poeppel (2015) for language and by Rushworth and colleagues (e.g., Apps et al., 2016) for other aspects of social cognition. Predictive coding is one potential example of a system-level computational approach to investigating mirror-neuron contributions to social cognition (Kilner et al., 2007; Press et al., 2011). Ideally, in any such approach, each hypothesis about function would specify a part in a psychological process-a process going all the way from peripheral sensory input to overt motor outputthat mirror neurons are thought to fulfill and do this in a way that is testable using behavioral and neurophysiological methods. The name given to this part is not important in itself. What is important is that the name does not derive its meaning purely from folk psychology and that the hypothetical function of mirror neurons is distinguished clearly from other components and from the overall process. For example, movement discrimination or action recognition (component) needs to be distinguished from mentalizing (whole process). Likewise, on the neurological side, we need more specific, testable theories of how mirror neurons work with other types of neurons and the kinds of networks in which they are embedded (including distinguishing whether any differences in function are due to regionor species-specific differences in mirror neurons themselves or the properties of the region or organism in which they are located). The term "mirror-neuron system" is commonly used, but proponents of this term need to specify the sense in which mirror neurons 
constitute a system rather than just cells with similar properties found in interconnected areas of the brain.

At the broadest, conceptual level, we need to think hard about why, if at all, it is important that single neurons have mirror properties. Setting aside the historical appeal of atomism, does it really matter in the context of contemporary psychology and neuroscience whether individual neurons or small networks of neurons match observed and executed actions? Indeed, in a potentially welcome development, recent single-unit recording studies indicate a move away from considering the properties of individual neurons and instead focus on population-level encoding. For example, individual neurons responsive to the observation of others' manipulative actions (grasping, dragging, etc.) in anterior intraparietal area show viewpoint-dependent coding, but as a population, they provide viewpoint-invariant coding of the observed action (Lanzilotto et al., 2020; for a similar demonstration of population encoding of observed actions in presupplementary motor area, see also Livi et al., 2019).

In conclusion, it turns out that mirror neurons contribute to complex control systems rather than dominating such systems or acting alone. Their contributions are at a relatively low level—for example, to body movement discrimination rather than intention reading. And rather than being immutable units from birth, mirror neurons acquire their mirror properties through sensorimotor learning and change them by the same route. Although disappointing relative to some early claims, we argue that these discoveries should not discourage further research on mirror neurons. The findings reviewed in this article suggest that when mirror neurons are studied in the context of system-level theory-as having the potential to fulfill a specified part in a complex processthey can help researchers to understand the categorization of body movements, aspects of speech perception, and the neurological bases of imitation. Furthermore, the evidence that mirror neurons are forged by sensorimotor experience not only raises important questions about the sources of this experience in everyday life across cultures but also opens up the possibility that other neurocognitive mechanisms, once thought to be genetically inherited, are shaped by cultural learning (Heyes, 2018). Mirror neurons should not be tarnished; they are yet to fulfill their true promise.

\section{Transparency}

Action Editor: Aina Puce

Editor: Laura A. King

Declaration of Conflicting Interests

The author(s) declared that there were no conflicts of interest with respect to the authorship or the publication of this article.
Funding

This work was supported by All Souls College, Oxford, and the Leverhulme Trust (Grant PLP-2015-019 to C. Catmur).

\section{ORCID iD}

Cecilia Heyes (iD https://orcid.org/0000-0001-9119-9913

\section{Note}

1. The use of the term autistic is endorsed by many individuals with autism (see Kenny et al., 2016). We therefore use this term as well as "person-first" language (e.g., people with autism) to respect the wishes of autistic individuals.

\section{References}

Anisfeld, M. (1996). Only tongue protrusion modeling is matched by neonates. Developmental Review, 16, 149-161.

Apps, M. A., Rushworth, M. F., \& Chang, S. W. (2016). The anterior cingulate gyrus and social cognition: Tracking the motivation of others. Neuron, 90(4), 692-707.

Barchiesi, G., \& Cattaneo, L. (2013). Early and late motor responses to action observation. Social Cognitive and Affective Neuroscience, 8(6), 711-719.

Bardi, L., Bundt, C., Notebaert, W., \& Brass, M. (2015). Eliminating mirror responses by instructions. Cortex, 70, 128-136.

Bernier, R., Aaronson, B., \& McPartland, J. (2013). The role of imitation in the observed heterogeneity in EEG mu rhythm in autism and typical development. Brain and Cognition, 82, 69-75.

Binder, E., Dovern, A., Hesse, M. D., Ebke, M., Karbe, H., Saliger, J., Fink, G. R., \& Weiss, P. H. (2017). Lesion evidence for a human mirror neuron system. Cortex, 90, $125-137$.

Bird, G., Leighton, J., Press, C., \& Heyes, C. (2007). Intact automatic imitation of human and robot actions in autism spectrum disorders. Proceedings of the Royal Society B: Biological Sciences, 274, 3027-3031.

Blakesee, S. (2006, January 10). Cells that read minds. The New York Times. http://www.nytimes.com/2006/01/10/ science/10mirr.html

Bocher, M., Chisin, R., Parag, Y., Freedman, N., MeirWeil, Y., Lester, H., Mishani, E., \& Bonne, O. (2001). Cerebral activation associated with sexual arousal in response to a pornographic clip: A 15O-H2O PET study in heterosexual men. NeuroImage, 14, 105-117.

Bonini, L., Rozzi, S., Serventi, F. U., Simone, L., Ferrari, P. F., \& Fogassi, L. (2010). Ventral premotor and inferior parietal cortices make distinct contribution to action organization and intention understanding. Cerebral Cortex, 20, 1372-1385.

Brunsdon, V. E., Bradford, E. E., Smith, L., \& Ferguson, H. J. (2020). Short-term physical training enhances mirror system activation to action observation. Social Neuroscience, 15, 98-107.

Buccino, G., Binkofski, F., Fink, G. R., Fadiga, L., Fogassi, L., Gallese, V., Seitz, R. J., Zilles, K., Rizzolatti, G., \& Freund, 
H. J. (2001). Action observation activates premotor and parietal areas in somatotopic manner: An fMRI study. European Journal of Neuroscience, 13, 400-404.

Callan, D. E., Jones, J. A., \& Callan, A. (2014). Multisensory and modality specific processing of visual speech in different regions of the premotor cortex. Frontiers in Psychology, 5, Article 389. https://doi.org/10.3389/fpsyg.2014.00389

Campbell, M. E. J., Mehrkanoon, S., \& Cunnington, R. (2018). Intentionally not imitating: Insula cortex engaged for topdown control of action mirroring. Neuropsychologia, 111, 241-251.

Catmur, C. (2014). Unconvincing support for the role of mirror neurons in "action understanding": Commentary on Michael et al. (2014). Frontiers in Human Neuroscience, 8, Article 553. https://doi.org/10.3389/fnhum.2014.00553

Catmur, C., Gillmeister, H., Bird, G., Liepelt, R., Brass, M., \& Heyes, C. (2008). Through the looking glass: Countermirror activation following incompatible sensorimotor learning. European Journal of Neuroscience, 28, 12081215.

Catmur, C., Mars, R. B., Rushworth, M. F., \& Heyes, C. M. (2011). Making mirrors: Premotor cortex stimulation enhances mirror and counter-mirror motor facilitation. Journal of Cognitive Neuroscience, 23, 2352-2362.

Catmur, C., Walsh, V., \& Heyes, C. (2007). Sensorimotor learning configures the human mirror system. Current Biology, 17, 1527-1531.

Catmur, C., Walsh, V., \& Heyes, C. (2009). Associative sequence learning: The role of experience in the development of imitation and the mirror system. Philosophical Transactions of the Royal Society B: Biological Sciences, 364, 2369-2380.

Cattaneo, L., Fabbri-Destro, M., Boria, S., Pieraccini, C., Monti, A., Cossu, G., \& Rizzolatti, G. (2007). Impairment of actions chains in autism and its possible role in intention understanding. Proceedings of the National Academy of Sciences, USA, 104(45), 17825-17830.

Cavallo, A., Heyes, C., Becchio, C., Bird, G., \& Catmur, C. (2014). Timecourse of mirror and counter-mirror effects measured with transcranial magnetic stimulation. Social Cognitive and Affective Neuroscience, 9(8), 1082-1088.

Coll, M.-P., Bird, G., Catmur, C., \& Press, C. (2015). Crossmodal repetition effects in the mu rhythm indicate tactile mirroring during action observation. Cortex, 63, 121-131.

Coll, M.-P., Press, C., Hobson, H., Catmur, C., \& Bird, G. (2017). Crossmodal classification of mu rhythm activity during action observation and execution suggests specificity to somatosensory features of actions. The Journal of Neuroscience, 37(24), 5936-5947.

Cook, J. L., \& Bird, G. (2012). Atypical social modulation of imitation in autism spectrum conditions. Journal of Autism and Developmental Disorders, 42, 1045-1051.

Cook, R., Bird, G., Catmur, C., Press, C., \& Heyes, C. (2014). Mirror neurons: From origin to function. Behavioral and Brain Sciences, 37, 177-192.

Cook, R., Dickinson, A., \& Heyes, C. (2012). Contextual modulation of mirror and countermirror sensorimotor associations. Journal of Experimental Psychology: General, 141, $774-787$.
Cooper, R. P., Cook, R., Dickinson, A., \& Heyes, C. M. (2013). Associative (not Hebbian) learning and the mirror neuron system. Neuroscience Letters, 540, 28-36.

Copete, J. L., Nagai, Y., \& Asada, M. (2016). Motor development facilitates the prediction of others' actions through sensorimotor predictive learning. In 2016 Joint IEEE International Conference on Development and Learning and Epigenetic Robotics (pp. 223-229). Institute of Electrical and Electronics Engineers. https:// doi.org/10.1109/DEVLRN.2016.7846823

Cossu, G., Boria, S., Copioli, C., Bracceschi, R., Giuberti, V., Santelli, E., \& Gallese, V. (2012). Motor representation of actions in children with autism. PLOS ONE, 7(9), Article e44779. https://doi.org/10.1371/journal.pone.0044779

D'Ausilio, A., Maffongelli, L., Bartoli, E., Campanella, M., Ferrari, E., Berry, J., \& Fadiga, L. (2014). Listening to speech recruits specific tongue motor synergies as revealed by transcranial magnetic stimulation and tissueDoppler ultrasound imaging. Philosophical Transactions of the Royal Society of London, Series B: Biological Sciences, 369(1644), Article 20130418. https://doi.org/10.1098/ rstb. 2013.0418

Davis, J., Redshaw, J., Suddendorf, T., Nielsen, M., KennedyCostantini, S., Oostenbroek, J., \& Slaughter, V. (2021). Does neonatal imitation exist? Insights from a metaanalysis of 336 effect sizes. Perspectives on Psychological Science. Advance online publication. https://doi.org/ $10.1177 / 1745691620959834$

Decety, J., Grèzes, J., Costes, N., Perani, D., Jeannerod, M., Procyk, E., Grassi, F., \& Fazio, F. (1997). Brain activity during observation of actions. Influence of action content and subject's strategy. Brain, 120, 1763-1777.

de Klerk, C. C., Johnson, M. H., Heyes, C. M., \& Southgate, V. (2015). Baby steps: Investigating the development of perceptual-motor couplings in infancy. Developmental Science, 18, 270-280.

de Klerk, C. C., Lamy-Yang, I., \& Southgate, V. (2019). The role of sensorimotor experience in the development of mimicry in infancy. Developmental Science, 22, Article e12771. https://doi.org/10.1111/desc.12771

Del Giudice, M., Manera, V., \& Keysers, C. (2009). Programmed to learn? The ontogeny of mirror neurons. Developmental Science, 12, 350-363.

Dennett, D. C. (1984). Elbow room: The varieties of free will worth wanting. Oxford University Press.

Dinstein, I. (2008). Human cortex: Reflections of mirror neurons. Current Biology, 18, R956-R959.

Dinstein, I., Hasson, U., Rubin, N., \& Heeger, D. J. (2007). Brain areas selective for both observed and executed movements. Journal of Neurophysiology, 98, 1415-1427.

di Pellegrino, G., Fadiga, L., Fogassi, L., Gallese, V., \& Rizzolatti, G. (1992). Understanding motor events: A neurophysiological study. Experimental Brain Research, 91, 176-180.

Dushanova, J., \& Donoghue, J. (2010). Neurons in primary motor cortex engaged during action observation. European Journal of Neuroscience, 31, 386-398.

Enticott, P. G., Kennedy, H. A., Rinehart, N. J., Bradshaw, J. L., Tonge, B. J., Daskalakis, Z. J., \& Fitzgerald, P. B. (2013). 
Interpersonal motor resonance in autism spectrum disorder: Evidence against a global "mirror system" deficit. Frontiers in Human Neuroscience, 7, Article 218. https:// doi.org/10.3389/fnhum.2013.00218

Enticott, P. G., Kennedy, H. A., Rinehart, N. J., Tonge, B. J., Bradshaw, J. L., Taffe, J. R., Daskalakis, Z. J., \& Fitzgerald, P. B. (2012). Mirror neuron activity associated with social impairments but not age in autism spectrum disorder. Biological Psychiatry, 71(5), 427-433.

Ferrari, P. F., Gallese, V., Rizzolatti, G., \& Fogassi, L. (2003). Mirror neurons responding to the observation of ingestive and communicative mouth actions in the monkey ventral premotor cortex. European Journal of Neuroscience, 17, 1703-1714.

Ferrari, P. F., Paukner, A., Ruggiero, A., Darcey, L., Unbehagen, S., \& Suomi, S. J. (2009). Interindividual differences in neonatal imitation and the development of action chains in rhesus macaques. Child Development, 80, 1057-1068.

Ferrari, P. F., Visalberghi, E., Paukner, A., Fogassi, L., Ruggiero, A., \& Suomi, S. J. (2006). Neonatal imitation in rhesus macaques. PLOS Biology, 4, Article e302. https:// doi.org/10.1371/journal.pbio.0040302

Fitzgibbon, B. M., Kirkovski, M., Fornito, A., Paton, B., Fitzgerald, P. B., \& Enticott, P. G. (2016). Emotion processing fails to modulate putative mirror neuron response to trained visuomotor associations. Neuropsychologia, 84, $7-13$.

Fogassi, L., Ferrari, P. F., Gesierich, B., Rozzi, S., Chersi, F., \& Rizzolatti, G. (2005). Parietal lobe: From action organization to intention understanding. Science, 308, 662-667.

Frenkel-Toledo, S., Liebermann, D. G., Bentin, S., \& Soroker, N. (2016). Dysfunction of the human mirror neuron system in ideomotor apraxia: Evidence from mu suppression. Journal of Cognitive Neuroscience, 28(6), 775-791.

Furukawa, Y., Uehara, K., \& Furuya, S. (2017). Expertisedependent motor somatotopy of music perception. Neuroscience Letters, 650, 97-102.

Gallese, V., Fadiga, L., Fogassi, L., \& Rizzolatti, G. (1996). Action recognition in the premotor cortex. Brain, 119, 593-609.

Gallese, V., Gernsbacher, M. A., Heyes, C., Hickok, G., \& Iacoboni, M. (2011). Mirror neuron forum. Perspectives on Psychological Science, 6, 369-407.

Gallese, V., Rochat, M., Cossu, G., \& Sinigaglia, C. (2009). Motor cognition and its role in the phylogeny and ontogeny of intentional understanding. Developmental Psychology, 45, 103-113.

Glenberg, A. M. (2011a). Introduction to the mirror neuron forum. Perspectives on Psychological Science, 6, 363-368.

Glenberg, A. M. (2011b). Positions in the mirror are closer than they appear. Perspectives on Psychological Science, 6, 408-410.

Gordon, A., Geddert, R., Hogeveen, J., Krug, M. K., Obhi, S., \& Solomon, M. (2020). Not so automatic imitation: Expectation of incongruence reduces interference in both autism spectrum disorder and typical development. Journal of Autism and Developmental Disorders, 50, 1310-1323.
Gowen, E., Stanley, J., \& Miall, R. C. (2008). Movement interference in autism spectrum disorder. Neuropsychologia, 46, 1060-1068.

Grezes, J., \& Decety, J. (2001). Functional anatomy of execution, mental simulation, observation, and verb generation of actions: A meta-analysis. Human Brain Mapping, 12, $1-19$.

Guidali, G., Carneiro, M. I., \& Bolognini, N. (2020). Paired Associative Stimulation drives the emergence of motor resonance. Brain Stimulation, 13, 627-636.

Hamilton, A. F. (2013). Reflecting on the mirror neuron system in autism: A systematic review of current theories. Developmental Cognitive Neuroscience, 3, 91-105.

Heiser, M., Iacoboni, M., Maeda, F., Marcus, J., \& Mazziotta, J. C. (2003). The essential role of Broca's area in imitation. European Journal of Neuroscience, 17, 1123-1128.

Heyes, C. (2001). Causes and consequences of imitation. Trends in Cognitive Sciences, 5, 253-261.

Heyes, C. (2010). Mesmerising mirror neurons. Neurolmage, 51, 789-791.

Heyes, C. (2013). A new approach to mirror neurons: Developmental history, system-level theory and intervention experiments. Cortex, 49(10), 2946-2948.

Heyes, C. (2018). Cognitive gadgets: The cultural evolution of thinking. Harvard University Press.

Hickok, G. (2014). The myth of mirror neurons: The real neuroscience of communication and cognition. W. W. Norton \& Company.

Hickok, G., Costanzo, M., Capasso, R., \& Miceli, G. (2011). The role of Broca's area in speech perception: Evidence from aphasia revisited. Brain E Language, 119(3), 214-220.

Hickok, G., \& Poeppel, D. (2015). Neural basis of speech perception. In G. Hickok \& S. L. Small (Eds.), Handbook of clinical neurology (Vol. 129, pp. 149-160). Elsevier.

Hobson, H. M., \& Bishop, D. V. M. (2016). Mu suppressionA good measure of the human mirror neuron system? Cortex, 82, 290-310.

Hobson, H. M., \& Bishop, D. V. M. (2017). The interpretation of mu suppression as an index of mirror neuron activity: Past, present and future. Royal Society Open Science, 4(3), Article 160662. https://doi.org/10.1098/rsos.160662

Hogeveen, J., Obhi, S. S., Banissy, M. J., Santiesteban, I., Press, C., Catmur, C., \& Bird, G. (2015). Task-dependent and distinct roles of the temporoparietal junction and inferior frontal cortex in the control of imitation. Social Cognitive and Affective Neuroscience, 10(7), 1003-1009.

Hou, J., Rajmohan, R., Fang, D., Kashfi, K., Al-Khalil, K., Yang, J., Westney, W., Grund, C. M., \& O'Boyle, M. W. (2017). Mirror neuron activation of musicians and nonmusicians in response to motion captured piano performances. Brain and Cognition, 115, 47-55.

Iacoboni, M. (2008). Mirroring people: The new science of how we connect with others. Farrar, Straus and Giroux.

Iacoboni, M., \& Dapretto, M. (2006). The mirror neuron system and the consequences of its dysfunction. Nature Reviews Neuroscience, 7(12), 942-951.

Jarrett, C. B. (2012, December 10). Mirror neurons: The most hyped concept in neuroscience? Psychology Today. http:// 
www.psychologytoday.com/blog/brain-myths/201212/ mirror-neurons-the-most-hyped-concept-in-neuroscience

Jones, S. S. (2006). Exploration or imitation? The effect of music on 4-week-old infants' tongue protrusions. Infant Behavior and Development, 29, 126-130.

Kaburu, S. S., Paukner, A., Simpson, E. A., Suomi, S. J., \& Ferrari, P. F. (2016). Neonatal imitation predicts infant rhesus macaque (Macaca mulatta) social and anxietyrelated behaviours at one year. Scientific Reports, 6, Article 34997. https://doi.org/10.1038/srep34997

Kenny, L., Hattersley, C., Molins, B., Buckley, C., Povey, C., \& Pellicano, E. (2016). Which terms should be used to describe autism? Perspectives from the UK autism community. Autism, 20(4), 442-462.

Keven, N., \& Akins, K. A. (2017). Neonatal imitation in context: Sensorimotor development in the perinatal period. Behavioral and Brain Sciences, 40, Article e381. https:// doi.org/10.1017/S0140525X16000911

Keysers, C., \& Perrett, D. I. (2004). Demystifying social cognition: A Hebbian perspective. Trends in Cognitive Sciences, 8, 501-507.

Kilner, J. M., Friston, K. J., \& Frith, C. D. (2007). The mirrorneuron system: A Bayesian perspective. NeuroReport, 18(6), 619-623.

Kilner, J. M., \& Lemon, R. N. (2013). What we know currently about mirror neurons. Current Biology, 23, R1057-R1062.

Kilner, J. M., Neal, A., Weiskopf, N., Friston, K. J., \& Frith, C. D. (2009). Evidence of mirror neurons in human inferior frontal gyrus. The Journal of Neuroscience, 29, 10153-10159.

Lanzilotto, M., Maranesi, M., Livi, A., Ferroni, C. G., Orban, G. A., \& Bonini, L. (2020). Stable readout of observed actions from format-dependent activity of monkey's anterior intraparietal neurons. Proceedings of the National Academy of Sciences, USA, $117(28), 16596-16605$.

Lehrer, J. (2008, July 1). The mirror neuron revolution: Explaining what makes humans social. Scientific American. https:// www.scientificamerican.com/article/the-mirror-neuronrevolut/

Livi, A., Lanzilotto, M., Maranesi, M., Fogassi, L., Rizzolatti, G., \& Bonini, L. (2019). Agent-based representations of objects and actions in the monkey pre-supplementary motor area. Proceedings of the National Academy of Sciences, USA, 116(7), 2691-2700.

Mainieri, A. G., Heim, S., Straube, B., Binkofski, F., \& Kircher, T. (2013). Differential role of the Mentalizing and the Mirror Neuron system in the imitation of communicative gestures. Neurolmage, 81, 294-305.

Markodimitraki, M., \& Kalpidou, M. (2019). Developmental changes in imitation during mother-infant interactions. Early Child Development and Care. Advance online publication. https://doi.org/10.1080/03004430.2019.1660962

McKyton, A., Ben-Zion, I., \& Zohary, E. (2018). Lack of automatic imitation in newly sighted individuals. Psychological Science, 29, 304-310.

Meltzoff, A. N. (1996). The human infant as an imitative generalist: A 20-year progress report on infant imitation with implications for comparative psychology. In C. M. Heyes \& B. G. Galef (Eds.), Social learning in animals: The roots of culture (pp. 55-77). Academic Press.
Meltzoff, A. N., \& Moore, M. K. (1977). Imitation of facial and manual gestures by human neonates. Science, 198, 75-78.

Meltzoff, A. N., Murray, L., Simpson, E., Heimann, M., Nagy, E., Nadel, J., Pedersen, E. J., Brooks, R., Messinger, D. S., Pascalis, L. D., Subiaul, F., \& Ferrari, P. (2018). Re-examination of Oostenbroek et al. (2016): Evidence for neonatal imitation of tongue protrusion. Developmental Science, 21, Article e12609. https://doi.org/10.1111/ desc.12609

Mengotti, P., Corradi-Dell'acqua, C., \& Rumiati, R. I. (2012). Imitation components in the human brain: An fMRI study. NeuroImage, 59(2), 1622-1630.

Michael, J., Sandberg, K., Skewes, J., Wolf, T., Blicher, J., Overgaard, M., \& Frith, C. D. (2014). Continuous thetaburst stimulation demonstrates a causal role of premotor homunculus in action understanding. Psychological Science, 25(4), 963-972.

Molenberghs, P., Cunnington, R., \& Mattingley, J. B. (2012). Brain regions with mirror properties: A meta-analysis of 125 human fMRI studies. Neuroscience and Biobehavioral Reviews, 36, 341-349.

Mukamel, R., Ekstrom, A. D., Kaplan, J., Iacoboni, M., \& Fried, I. (2010). Single neuron responses in humans during execution and observation of actions. Current Biology, 20, 750-756.

Murray, L., Bozicevic, L., Ferrari, P. F., Vaillancourt, K., Dalton, L., Goodacre, T., Chakrabarti, B., Bicknell, S., Cooper, P., Stein, A., \& De Pascalis, L. (2018). The effects of maternal mirroring on the development of infant social expressiveness: The case of infant cleft lip. Neural Plasticity, 2018, Article 5314657. https://doi.org/10.1155/2018/5314657s

Newman-Norlund, R. D., Ondobaka, S., van Schie, H. T., van Elswijk, G., \& Bekkering, H. (2010). Virtual lesions of the IFG abolish response facilitation for biological and nonbiological cues. Frontiers in Behavioral Neuroscience, 4, Article 5. https://doi.org/10.3389/neuro.08.005.2010

Nuttall, H. E., Kennedy-Higgins, D., Devlin, J. T., \& Adank, P. (2017). The role of hearing ability and speech distortion in the facilitation of articulatory motor cortex. Neuropsychologia, 94, 13-22.

Nuttall, H. E., Kennedy-Higgins, D., Devlin, J. T., \& Adank, P. (2018). Modulation of intra- and inter-hemispheric connectivity between primary and premotor cortex during speech perception. Brain \& Language, 187, 74-82.

Nuttall, H. E., Kennedy-Higgins, D., Hogan, J., Devlin, J. T., \& Adank, P. (2016). The effect of speech distortion on the excitability of articulatory motor cortex. NeuroImage, 128, 218-226.

Oberman, L. M., \& Ramachandran, V. S. (2007). The simulating social mind: The role of the mirror neuron system and simulation in the social and communicative deficits of autism spectrum disorders. Psychological Bulletin, 133(2), 310-327.

Ocampo, B., Kritikos, A., \& Cunnington, R. (2011). How frontoparietal brain regions mediate imitative and complementary actions: An FMRI study. PLOS ONE, 6(10), Article e26945. https://doi.org/10.1371/journal.pone.0026945

Oostenbroek, J., Redshaw, J., Davis, J., Kennedy-Costantini, S., Nielsen, M., Slaughter, V., \& Suddendorf, T. (2018). 
Re-evaluating the neonatal imitation hypothesis. Developmental Science, 22, Article e12720. https://doi.org/10 $.1111 /$ desc. 12720

Oostenbroek, J., Suddendorf, T., Nielsen, M., Redshaw, J., Kennedy-Costantini, S., Davis, J., Clark, S., \& Slaughter, V. (2016). Comprehensive longitudinal study challenges the existence of neonatal imitation in humans. Current Biology, 26, 1334-1338.

Orlandi, A., Zani, A., \& Proverbio, A. M. (2017). Dance expertise modulates visual sensitivity to complex biological movements. Neuropsychologia, 104, 168-181.

Orofino, G. (1994). Divination with mirrors. In P. Kavaerne (Ed.), Tibetan studies (Vol. 2, pp. 612-628). Institute for Comparative Research in Human Culture.

Panouilleres, M. T. N., Boyles, R., Chesters, J., Watkins, K. E., \& Mottonen, R. (2018). Facilitation of motor excitability during listening to spoken sentences is not modulated by noise or semantic coherence. Cortex, 103, 44-54.

Pascolo, P. B., \& Cattarinussi, A. (2012). On the relationship between mouth opening and "broken mirror neurons" in autistic individuals. Journal of Electromyography and Kinesiology, 22(1), 98-102.

Paukner, A., Ferrari, P. F., \& Suomi, S. J. (2011). Delayed imitation of lipsmacking gestures by infant rhesus macaques. PLOS ONE, 6(12), Article e0028848. https:// doi.org/10.1371/journal.pone.0028848

Paukner, A., Pedersen, E. J., \& Simpson, E. A. (2017). Testing the arousal hypothesis of neonatal imitation in infant rhesus macaques. PLOS ONE, 12(6), Article e0178864. https://doi.org/10.1371/journal.pone.0178864

Paukner, A., Simpson, E. A., Ferrari, P. F., Mrozek, T., \& Suomi, S. J. (2014). Neonatal imitation predicts how infants engage with faces. Developmental Science, 17 , 833-840.

Pokorny, J. J., Hatt, N. V., Colombi, C., Vivanti, G., Rogers, S. J., \& Rivera, S. M. (2015). The action observation system when observing hand actions in autism and typical development. Autism Research, 8(3), 284-296.

Press, C., Catmur, C., Cook, R., Widman, H., Heyes, C., \& Bird, G. (2012). fMRI evidence of 'mirror' responses to geometric shapes. PLOS ONE, 7(12), Article e51934. https://doi .org/10.1371/journal.pone.0051934

Press, C., Heyes, C., \& Kilner, J. M. (2011). Learning to understand others' actions. Biology Letters, 7(3), 457-460.

Press, C., Richardson, D., \& Bird, G. (2010). Intact imitation of emotional facial actions in autism spectrum conditions. Neuropsychologia, 48, 3291-3297.

Ramachandran, V. S. (2009, November). The neurons that shaped civilization [Video]. TED Conferences. http:// www.ted.com/talks/vs_ramachandran_the_neurons_that_ shaped_civilization.html

Ray, E., \& Heyes, C. (2011). Imitation in infancy: The wealth of the stimulus. Developmental Science, 14, 92-105.

Rayson, H., Bonaiuto, J. J., Ferrari, P. F., \& Murray, L. (2017). Early maternal mirroring predicts infant motor system activation during facial expression observation. Scientific Reports, 7, Article 11738. https://doi.org/10.1038/s41598017-12097-W

Reader, A. T., Royce, B. P., Marsh, J. E., Chivers, K. J., \& Holmes, N. P. (2018). Repetitive transcranial magnetic stimulation reveals a role for the left inferior parietal lobule in matching observed kinematics during imitation. European Journal of Neuroscience, 47(8), 918-928.

Redshaw, J. (2019). Re-analysis of data reveals no evidence for neonatal imitation in rhesus macaques. Biology Letters, 15(7), Article 20190342. https://doi.org/10.1098/ rsbl.2019.0342

Reeb-Sutherland, B. C., Levitt, P., \& Fox, N. A. (2012). The predictive nature of individual differences in early associative learning and emerging social behavior. PLOS ONE, 7(1), Article e0030511. https://doi.org/10.1371/journal .pone.0030511

Restle, J., Murakami, T., \& Ziemann, U. (2012). Facilitation of speech repetition accuracy by theta burst stimulation of the left posterior inferior frontal gyrus. Neuropsychologia, 50(8), 2026-2031.

Rizzolatti, G., \& Craighero, L. (2004). The mirror-neuron system. Annual Review of Neuroscience, 27, 169-192.

Rizzolatti, G., Fadiga, L., Gallese, V., \& Fogassi, L. (1996). Premotor cortex and the recognition of motor actions. Social Cognitive and Affective Neuroscience, 3, 131-141.

Rizzolatti, G., \& Sinigaglia, C. (2008). Mirrors in the brain. Oxford University Press.

Rizzolatti, G., \& Sinigaglia, C. (2010). The functional role of the parieto-frontal mirror circuit: Interpretations and misinterpretations. Nature Reviews Neuroscience, 11, 264-274.

Rogalsky, C., Love, T., Driscoll, D., Anderson, S. W., \& Hickok, G. (2011). Are mirror neurons the basis of speech perception? Evidence from five cases with damage to the purported human mirror system. Neurocase, 17(2), 178-187.

Rogers, J. C., Mottonen, R., Boyles, R., \& Watkins, K. E. (2014). Discrimination of speech and non-speech sounds following theta-burst stimulation of the motor cortex. Frontiers in Psychology, 5, Article 754. https://doi.org/10.3389/ fpsyg.2014.00754

Ruggiero, M., \& Catmur, C. (2018). Mirror neurons and intention understanding: Dissociating the contribution of object type and intention to mirror responses using electromyography. Psychophysiology, 55(7), Article e13061. https://doi.org/10.1111/psyp.13061

Ruysschaert, L., Warreyn, P., Wiersema, J. R., Oostra, A., \& Roeyers, H. (2014). Exploring the role of neural mirroring in children with autism spectrum disorder. Autism Research, 7(2), 197-206.

Schulte-Ruther, M., Otte, E., Adiguzel, K., Firk, C., HerpertzDahlmann, B., Koch, I., \& Konrad, K. (2017). Intact mirror mechanisms for automatic facial emotions in children and adolescents with autism spectrum disorder. Autism Research, 10(2), 298-310.

Schunke, O., Schottle, D., Vettorazzi, E., Brandt, V., Kahl, U., Bäumer, T., Ganos, C., David, N., Peiker, I., Engel, A. K., Brass, M., \& Münchau, A. (2016). Mirror me: Imitative responses in adults with autism. Autism, 20(2), 134-144. https://doi.org/10.1177/1362361315571757

Simpson, E. A., Miller, G. M., Ferrari, P. F., Suomi, S. J., \& Paukner, A. (2016). Neonatal imitation and early social experience predict gaze following abilities in infant monkeys. Scientific Reports, 6, Article 20233. https://doi .org/10.1038/srep20233 
Simpson, E. A., Paukner, A., Sclafani, V., Suomi, S. J., \& Ferrari, P. F. (2013). Lipsmacking imitation skill in newborn macaques is predictive of social partner discrimination. PLOS ONE, 8(12), Article e0082921. https://doi .org/10.1371/journal.pone.0082921

Simpson, E. A., Paukner, A., Suomi, S. J., \& Ferrari, P. F. (2014). Visual attention during neonatal imitation in newborn macaque monkeys. Developmental Psychobiology, $56,864-870$.

Smalle, E. H., Rogers, J., \& Mottonen, R. (2015). Dissociating contributions of the motor cortex to speech perception and response bias by using transcranial magnetic stimulation. Cerebral Cortex, 25(10), 3690-3698.

Southgate, V., \& Hamilton, A. F. (2008). Unbroken mirrors: Challenging a theory of autism. Trends in Cognitive Sciences, 12, 225-229.

Sowden, S., Koehne, S., Catmur, C., Dziobek, I., \& Bird, G. (2016). Intact automatic imitation and typical spatial compatibility in Autism Spectrum Disorder: Challenging the Broken Mirror Theory. Autism Research, 9(2), 292-300.

Spengler, S., Bird, G., \& Brass, M. (2010). Hyperimitation of actions is related to reduced understanding of others' minds in autism spectrum conditions. Biological Psychiatry, 68, 1148-1155.

Stasenko, A., Bonn, C., Teghipco, A., Garcea, F. E., Sweet, C., Dombovy, M., McDonough, J., \& Mahon, B. Z. (2015). A causal test of the motor theory of speech perception: A case of impaired speech production and spared speech perception. Cognitive Neuropsychology, 32(2), 38-57.

Tarhan, L. Y., Watson, C. E., \& Buxbaum, L. J. (2015). Shared and distinct neuroanatomic regions critical for tool-related action production and recognition: Evidence from 131 left-hemisphere stroke patients. Journal of Cognitive Neuroscience, 27(12), 2491-2511.

Thompson, E. L., Bird, G., \& Catmur, C. (2019). Conceptualizing and testing action understanding. Neuroscience and Biobehavioral Reviews, 105, 106-114.

Tkach, D., Reimer, J., \& Hatsopoulos, N. G. (2007). Congruent activity during action and action observation in motor cortex. The Journal of Neuroscience, 27, 13241-13250.

Ubaldi, S., Barchiesi, G., \& Cattaneo, L. (2015). Bottom-up and top-down visuomotor responses to action observation. Cerebral Cortex, 25(4), 1032-1041.
Urgesi, C., Candidi, M., \& Avenanti, A. (2014). Neuroanatomical substrates of action perception and understanding: An anatomic likelihood estimation meta-analysis of lesionsymptom mapping studies in brain injured patients. Frontiers in Human Neuroscience, 8, Article 344. https:// doi.org/10.3389/fnhum.2014.00344

Vannuscorps, G., \& Caramazza, A. (2016). Typical action perception and interpretation without motor simulation. Proceedings of the National Academy of Sciences, USA, 113(1), 86-91.

Whiten, A. (2002). The imitator's representation of the imitated: Ape and child. In A. N. Meltzoff \& W. Prinz (Eds.), The imitative mind: Development, evolution, and brain bases (pp. 99-121). Cambridge University Press.

Wiggett, A. J., Hudson, M., Clifford, A., Tipper, S. P., \& Downing, P. E. (2012). Doing, seeing, or both: Effects of learning condition on subsequent action perception. Social Neuroscience, 7, 606-621.

Williams, J. H., Whiten, A., Suddendorf, T., \& Perrett, D. I. (2001). Imitation, mirror neurons and autism. Neuroscience and Biobehavioral Reviews, 25, 287-295.

Wooddell, L. J., Simpson, E. A., Murphy, A. M., Dettmer, A. M., \& Paukner, A. (2019). Interindividual differences in neonatal sociality and emotionality predict juvenile social status in rhesus monkeys. Developmental Science, 22(2), Article e12749. https://doi.org/10.1111/desc.12749

Wurm, M. F., \& Caramazza, A. (2019). Distinct roles of temporal and frontoparietal cortex in representing actions across vision and language. Nature Communications, 10(1), Article 289. https://doi.org/10.1038/s41467-018-08084-y

Wurm, M. F., \& Lingnau, A. (2015). Decoding actions at different levels of abstraction. The Journal of Neuroscience, 35(20), 7727-7735.

Yang, J., \& Hofmann, J. (2016). Action observation and imitation in autism spectrum disorders: An ALE metaanalysis of fMRI studies. Brain Imaging \& Behavior, 10(4), 960-969.

Zazio, A., Guidali, G., Maddaluno, O., Miniussi, C., \& Bolognini, N. (2019). Hebbian associative plasticity in the visuo-tactile domain: A cross-modal paired associative stimulation protocol. NeuroImage, 201, Article 116025. https://doi.org/10.1016/j.neuroimage.2019 .116025 